\title{
Update from the American Society of Clinical Oncology 2017 Genitourinary Cancers Symposium (ASCO-GU)
}

\section{Anil Kapoor, MD, FRCSC}

Professor of Surgery (Urology), McMaster University, Associate Editor (Oncology), Canadian Urological Association Journal (CUA), Hamilton, ON, Canada

Cite as: Can Urol Assoc J 2017;11 (6Suppl3):S159. http://dx.doi.org/10.5489/cuaj.4691

7

he American Society of Clinical Oncology Genitourinary Cancers Symposium (ASCO-GU) annual meeting provides cutting-edge, exciting research in GU malignancies. The 2017 edition was no exception, with relevant clinical research in all GU disease states. In this Canadian Urological Association (CUA) report, we have asked our Canadian oncology experts in bladder, kidney, prostate, and testes cancer to summarize the key messages from this year's symposium. We appreciate the support of our sponsors, Astellas, Bristol-Myers Squibb, Merck Canada, and Roche, which makes this report possible.

I hope you find this ASCO-GU 2017 summary informative and relevant for your practice.

Acknowledgement: The authors would like to thank STA Healthcare Communications for editorial assistance with this report.

Correspondence: Dr. Anil Kapoor, McMaster University, Hamilton, ON, Canada; akapoor@mcmaster.ca 